\title{
Processing of garlic: Present status and prospects
}

\author{
S.V. Bondre, A.M. Sonkamble and S.R. Patil
}

\begin{abstract}
India ranks at second position with share of 5.17 per cent of global area under garlic cultivation. Among dehydrated and processed garlic products viz., dehydrated garlic flakes, garlic slices or rings, garlic grits, garlic tablets, garlic pickles, garlic powders, digestive churns, paste, garlic salts are most demanded processed product at national and international level due to nutritional compositions, health benefits and medicinal properties of garlic. Nutritional quality and flavouring component wise Indian garlic is much better and as a result there is better demand in ethnic markets. The demand of dehydrated and processed food has increased to manifold in last few decades. India has emerged as prominent exporter of dried and preserved vegetables during last few years. In year 2015-16, totally 66189.62 MT dried and preserved vegetables are exported with earnings of foreign currency of Rs. 91420.85 Lac. Value addition through processing of the bulbs in the form of dehydrated flakes, dehydrated powder, paste, etc. will be instrumental in substantially expanding the export basket of garlic and its derivative products. Lot of market oriented research and efforts are needed in this prospect. There must be policy implementation for startup of garlic processing units in areas identified as production hub of quality garlic. Public-Private partnership in production and R\&D sectors will offer better opportunities to focus and elevate garlic processing industry in India.
\end{abstract}

Key Words : Garlic, Processing, Nutritional quality, Export

How to cite this article : Bondre, S.V., Sonkamble, AM. and Patil, S.R. (2017). Processing of garlic: Present status and prospects. Food Sci. Res. J., 8(2): 425-431, DOI : 10.15740/HAS/FSRJ/8.2/425-431. 